\title{
Safety and pharmacodynamic dose response of short-term prednisone in healthy adult subjects: a dose ranging, randomized, placebo-controlled, crossover study
}

Dona L. Fleishaker ${ }^{1}$, Arnab Mukherjee ${ }^{1 *}$, Fredrick S. Whaley ${ }^{2}$, Shanthini Daniel ${ }^{3}$ and Bernhardt G. Zeiher ${ }^{4}$

\begin{abstract}
Background: Glucocorticoids (GCs), such as prednisone, are the standard of care for several inflammatory and immunologically mediated diseases, but their chronic systemic administration is severely limited by serious adverse effects that are both dose and time dependent. Short-term treatment (7-14 days) with oral prednisone is used for many acute inflammatory and allergic conditions. This study was conducted to characterize the safety and pharmacodynamic (PD) dose-response of a 7-day course of oral prednisone on biomarkers of GC receptor agonism.

Methods: In this randomized, single-blind, placebo-controlled, crossover study (A9001309), 37 healthy subjects received placebo or a prednisone dose from 2.5-60 mg daily over 7 days in each of three treatment periods. White blood cell counts and plasma samples for measuring cortisol, osteocalcin and procollagen type $1 \mathrm{~N}$-propeptide (P1NP) were obtained at 2, 4, 8, and $12 \mathrm{~h}$ post-dose on Day 1, immediately prior to dosing on Days 1, 2, and 4, and at nominal dosing time on Days 0 and 8 . Urine samples for urinary N-terminal cross-linked telopeptide of type 1 collagen (UNTX) were collected on Days 0, 1, 2, 4, and 8. Serum samples for adiponectin were obtained prior to dosing on days $0,1,4$ and 8.

Results: Daily doses of prednisone up to $60 \mathrm{mg}$ resulted in dose- and time-dependent decreases in plasma osteocalcin, plasma P1NP, serum cortisol, and absolute blood eosinophil counts. Absolute blood neutrophil counts increased, while blood lymphocyte counts rebounded to an increased level following an initial rapid decrease after dosing. An increase was observed for UNTX and adiponectin. The incidence of adverse effects with prednisone was not dose related, and nervous system disorders, mainly headache, were the most frequently reported adverse effects.

Conclusions: This characterization provides important and relevant information on safety and PD responses of short-term prednisone dosing over the commonly-used clinical dose range, and also provides a reference for early clinical development of dissociated agents targeting a differentiated PD profile.
\end{abstract}

Trial registration number: NCT02767089 (retrospectively registered: 21 April 2016).

Keywords: Biomarker, Dose-response, Glucocorticoid, Healthy-subject, Pharmacodynamic, Prednisone, Safety

* Correspondence: arnab.mukherjee@pfizer.com

${ }^{1}$ Pfizer Inc, Eastern Point Rd, Groton, CT 06340, USA

Full list of author information is available at the end of the article 


\section{Background}

Glucocorticoids (GCs) are commonly used to manage inflammatory and immunologically-mediated conditions [1-3], and continue to have a prominent place in the clinic despite having a profile of serious adverse effects that are dose- and time-dependent [4, 5]. Due to these known serious adverse effects, a GC such as prednisone is used at the lowest effective dose (5-7.5 mg daily) for chronic conditions such as rheumatoid arthritis (RA); the use of higher doses is limited to the shortest treatment duration required for management of acute conditions and disease exacerbations [6, 7]. One of the most prevalent adverse effects is that on bone remodeling, specifically, an uncoupling of bone formation and resorption in favor of bone loss via direct effects on osteoblasts [8]. Indeed, the most common form of iatrogenic osteoporosis is GC induced [9]. Many other adverse effects, such as electrolyte imbalance, weight gain, and metabolic disturbances, result from GC-induced effects on other tissues including the hypothalamic-pituitary-adrenal (HPA) axis $[10,11]$. Similarly, due to a plethora of effects on leukocytes and vascular endothelial cells, such as altered cell distribution patterns, immobilization, and apoptosis, GC therapy can result in dramatic changes in circulating white blood cell profiles that may contribute to an increased risk of GC-associated infection [12-14].

Recent drug discovery and development efforts have focused on approaches to reduce adverse effects, while maintaining efficacy of GC therapy. These approaches include development of a modified-release prednisone formulation and discovery of selective GC receptor ligands that putatively dissociate anti-inflammatory effects mediated by genomic transrepression from adverse effects mediated by genomic transactivation [7, 15-18]. Despite the present understanding of the known adverse effects of GC therapy, and recent drug development efforts to potentially dissociate efficacy and safety of GCs, the dose-response and time course of the effect of current GCs on various biomarkers of GC receptor agonism (anti-inflammatory and adverse effects) have not been systematically characterized. The characterization of the safety and pharmacodynamics (PD) of multiple doses of a standard GC such as prednisone, over the commonly used clinical dose range (2.5-60 mg once daily), provides important and relevant information for clinical use, as well as reference for early clinical development of dissociated agents targeting a differentiated PD profile.

The present study was conducted to further characterize the safety and dose-response of 7-day prednisone administration using biomarkers of GC receptor agonism in a healthy adult population.

\section{Methods}

\section{Subjects}

Eligible subjects were healthy adult volunteers aged 18-55 years (male) or 18-44 years (female), with a body mass index of $18-30 \mathrm{~kg} / \mathrm{m}^{2}$ and a total body weight $>50 \mathrm{~kg}$ (110 lb). Subjects with evidence or history of clinically significant hematologic, renal, endocrine, pulmonary, gastrointestinal, cardiovascular, hepatic, psychiatric, neurologic, or allergic disease (including drug allergies, but excluding untreated, asymptomatic seasonal allergies at time of dosing) or any condition possibly affecting drug absorption were excluded from the study.

\section{Study design}

This randomized, single-blind, placebo-controlled, crossover study (A9001309) was designed to characterize the dose-response of prednisone on biomarkers of GC receptor agonism. Within 28 days of screening, all eligible subjects were randomly assigned to one of seven treatment sequences, each with three 7-day treatment periods separated by a 14-day washout period (Table 1). The treatments in each sequence included either three of the six prednisone doses evaluated in the study $(2.5,5,10,20$, 40 , or $60 \mathrm{mg}$ ), or two prednisone doses and placebo. In the first treatment period only, all subjects had baseline assessments on Day 0, the day prior to dosing.

\section{Biomarker evaluations and analytic methods HPA axis}

Serum samples for morning cortisol were obtained immediately prior to dosing or nominal dosing time on Day 0 (baseline, day prior to first dosing) and on Days 1 (first day of dosing), 2, 4, and 8, in each of the three 7-day treatment periods. Serum samples for cortisol were obtained at 2, 4, 8, and $12 \mathrm{~h}$ following the first sample on Day 0 (Period 1 only) and following the first prednisone dose on Day 1. A radioimmunoassay (Roche Diagnostics,

Table 1 Treatment sequences

\begin{tabular}{lllll}
\hline Treatment & Subjects, & \multicolumn{3}{l}{ Treatment period } \\
\cline { 3 - 5 } sequence & $n$ & & 2 & 3 \\
\hline A & 5 & Placebo & $2.5 \mathrm{mg}$ & $10 \mathrm{mg}$ \\
B & 5 & $2.5 \mathrm{mg}$ & $5 \mathrm{mg}$ & $20 \mathrm{mg}$ \\
C & 5 & $5 \mathrm{mg}$ & $10 \mathrm{mg}$ & $40 \mathrm{mg}$ \\
D & 5 & $10 \mathrm{mg}$ & $20 \mathrm{mg}$ & $60 \mathrm{mg}$ \\
E & 5 & $20 \mathrm{mg}$ & $40 \mathrm{mg}$ & Placebo \\
F & 5 & $40 \mathrm{mg}$ & $60 \mathrm{mg}$ & $2.5 \mathrm{mg}$ \\
G & 5 & $60 \mathrm{mg}$ & Placebo & $5 \mathrm{mg}$ \\
Total & $35^{\mathrm{a}}$ & & &
\end{tabular}

Doses shown correspond to the daily prednisone dose administered for 7 days in each treatment period

${ }^{\text {aTwo }}$ subjects discontinued the study during Period 2 and were replaced following approval by the study statistician 
Indianapolis, IN) was used initially for measurement of cortisol in serum, but the results indicated the possibility of assay interference from prednisone and its metabolite prednisolone. Consequently, a specific, validated, highperformance liquid chromatography assay (calibration range, $10-3000 \mathrm{ng} / \mathrm{mL}$ ) with tandem mass spectrometry (SGS Cephac, Poitiers, France) was used to assay cortisol in plasma samples collected for osteocalcin (OC) measurement on Day 0 and Day 1 (pre-dose and 2, 4, 8, and $12 \mathrm{~h}$ post-dose) and prior to dosing on Day 2. These plasma samples were stored at $-70{ }^{\circ} \mathrm{C}$ until assayed for cortisol and had previously undergone one freeze-thaw cycle. Stability of cortisol was confirmed in plasma for a time period greater than the duration of storage with up to three freeze-thaw cycles.

Serum was also obtained for assaying cortisol levels on Day 8 before and $30 \mathrm{~min}$ after low-dose adrenocorticotropic hormone $(\mathrm{ACTH})$ stimulation. Subjects with an abnormal low-dose ACTH stimulation response on Day 8 were administered the test again after 2 weeks. A radioimmunoassay was used for measurement of serum cortisol from the low-dose ACTH stimulation test. Assay interference from prednisone and prednisolone was considered unlikely, since complete washout of both moieties was expected at the time these samples were obtained.

\section{White blood cell counts}

Complete blood count with differential (data for neutrophils, eosinophils, and lymphocytes are shown) was obtained at 2, 4, 8, and $12 \mathrm{~h}$ post-dose on Day 1, immediately prior to dosing on Days 1,2 , and 4 , and at nominal dosing time on Days 0 and 8 .

\section{Bone metabolism}

Plasma samples for OC, a biomarker of bone formation, were collected serially on Day 0 (at nominal dosing time and $2,4,8$, and $12 \mathrm{~h}$ thereafter) and serially post-dose on Day $1(2,4,8$, and $12 \mathrm{~h})$, immediately prior to dosing on Days 1, 2, and 4, and at nominal dosing time on Day 8; plasma samples for procollagen type $1 \mathrm{~N}$-propeptide (P1NP), also a bone formation marker, were collected $12 \mathrm{~h}$ post-dose on Day 1, immediately prior to dosing on Days 2 and 4, and on Days 0 and 8. Urine samples for urinary $\mathrm{N}$-terminal cross-linked telopeptide of type 1 collagen (uNTX), a biomarker of bone resorption, were collected from the second pre-noon voiding of the bladder on Days $0,1,2,4$, and 8. OC and uNTX were assayed using an enzyme-linked immunosorbent assay method. P1NP was assayed by a validated radioimmunoassay. A kinetic modification of the Jaffe reaction was used for the quantitative measurement of urinary creatinine $(\mathrm{uCr})$. Pacific Biometrics, Inc. (Seattle, WA, USA) kits were used for all four analytes.

\section{Carbohydrate and metabolic effects}

Serum samples for fasting glucose and insulin were obtained immediately prior to dosing on Days $0,1,2,4,6$, and 7 . For the oral glucose tolerance test (OGTT), the subjects were to ingest $75 \mathrm{~g}$ of a glucose solution within 5 min of receiving study medication on Day 6; this solution was to be ingested within $10 \mathrm{~min}$, and blood samples for glucose were then collected at $0.5,1$, and $2 \mathrm{~h}$. Serum samples for triglycerides were obtained immediately prior to dosing on Days 0,1 and 4, and on Day 8 and, for adiponectin, immediately prior to dosing on Days 0,1 and 4, and on Day 8. Serum samples were analyzed for adiponectin using a LINCO Diagnostics Services (St. Charles, MO, USA) radioimmunoassay; the validated range of the assay was $2-100 \mathrm{ng} / \mathrm{mL}$.

\section{Central nervous system}

Subjects were required to complete Profile of Mood State $\left(\mathrm{POMS}^{\mathrm{rm}}\right)$ and Medical Outcomes Study: Sleep Scale (MOS-Sleep) questionnaires on the evening of Days 0 and 7.

\section{Safety}

Adverse events (AEs) were monitored throughout, and vital signs (sitting blood pressure and pulse rate) were performed at screening and prior to dosing on Days 0,1 , 4, and 8; laboratory safety tests (hematology, blood chemistry, urinalysis, and hormone and chronic infection tests), were performed at screening and on Day 0; a post-void weight was taken at screening and on Days 1 and 8 of each treatment period.

\section{Statistical analyses}

The change from baseline in primary biomarker endpoints (biomarkers of AEs and biomarkers of anti-inflammatory activity) for each prednisone dose was compared with the change from baseline for placebo, using a repeatedmeasures crossover analysis of covariance model containing effects for sequence, period, time, dose, time by dose interaction, and subject within sequence (as random effect), as well as baseline as a covariate. For comparison with placebo, the least squares mean difference, standard error, $95 \%$ confidence interval, and $P$ value were reported.

\section{Results \\ Subjects}

Overall, 37 subjects were screened; all were assigned to study treatment. Five subjects were assigned to each of the seven treatment sequences (A-G) and received either three active doses of prednisone $2.5,5,10,20,40$, or $60 \mathrm{mg}$, or two active doses and placebo. Ultimately, each of the treatments was received by 15 or 16 subjects. The proportion of subjects completing the study was $91.9 \%$. Two subjects in treatment sequence $\mathrm{E}$ (prednisone 
$20 \mathrm{mg}, 40 \mathrm{mg}$, and placebo in Periods 1, 2, and 3, respectively) and one subject in treatment sequence $G$ (prednisone $60 \mathrm{mg}$, placebo, and prednisone $5 \mathrm{mg}$ in periods 1,2 , and 3 , respectively) discontinued from the study. The subject in treatment sequence $G$ discontinued during Period 2 while receiving placebo due to AEs related to the study treatment. The other two subjects discontinued from the study for reasons not related to study treatment; both subjects withdrew consent. One subject in treatment sequence $\mathrm{E}$ was also discontinued during Period 2 while receiving prednisone $40 \mathrm{mg}$; both subjects that discontinued during Period 2 were replaced following approval by the study statistician. The other subject in treatment sequence $\mathrm{E}$ was in treatment period 1 at discontinuation, and was not replaced.

\section{Baseline characteristics}

Demographic characteristics were similar among the treatment groups. Subjects were aged between 18 and 50 years, and the majority were white and male (Table 2 ).

\section{Effect of prednisone on markers of safety and efficacy HPA axis}

Plasma cortisol concentrations decreased rapidly following the first dose of prednisone, and then recovered in a dose-dependent manner (Fig. 1). Following single prednisone doses of $20 \mathrm{mg}$ and higher, all individual cortisol measurements at 8 and $12 \mathrm{~h}$ post-dose were below the lower limit of quantification $(10 \mathrm{ng} / \mathrm{mL})$, and mean predose cortisol concentrations in these dose groups on Day 2 were lower than the corresponding median values on Day 1 (baseline).

A low-dose ACTH stimulation test was carried out after completion of all treatment periods to assess whether each

Table 2 Demographic characteristics of all treatment groups

\begin{tabular}{llll}
\hline Characteristic & $\begin{array}{l}\text { Male } \\
(n=30)\end{array}$ & $\begin{array}{l}\text { Female } \\
(n=7)\end{array}$ & $\begin{array}{l}\text { Total } \\
(N=37)\end{array}$ \\
\hline $\begin{array}{lll}\text { Age, years } \\
\text { Mean (SD) }\end{array}$ & $\begin{array}{l}33.7(9.8) \\
\text { Range }\end{array}$ & $\begin{array}{l}35.6(6.7) \\
27-43\end{array}$ & $\begin{array}{l}34.1(9.2) \\
18-50\end{array}$ \\
$\begin{array}{l}\text { Race, } n \\
\text { White }\end{array}$ & 21 & 5 & 26 \\
Black & 7 & 1 & 8 \\
Other & 2 & 1 & 3 \\
Weight, kg & & & $80.0(10.3)$ \\
Mean (SD) & $81.3(10.2)$ & $74.4(9.2)$ & $57.2-101.6$ \\
Range & $57.2-101.6$ & $60.8-84.8$ & \\
Height, cm & & & $173.9(9.1)$ \\
Mean (SD) & $177.0(6.7)$ & $160.6(4.7)$ & $153.7-188.0$ \\
Range & $164.0-188.0$ & $153.7-167.0$ &
\end{tabular}

SD standard deviation

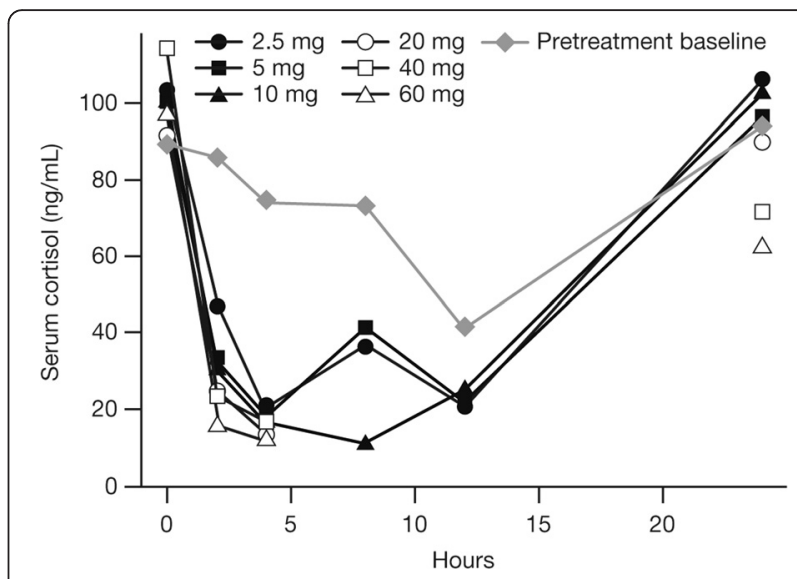

Fig. 1 Mean serum cortisol concentrations up to $24 \mathrm{~h}$ following the first daily dose of prednisone. Pretreatment cortisol concentrations over $24 \mathrm{~h}$ were measured in all subjects the day prior to the first day of dosing in Period 1

subject's HPA axis was adversely affected by prednisone. A normal response to ACTH was defined as an increase in serum cortisol to $>18 \mu \mathrm{g} / \mathrm{dL}$ within $30 \mathrm{~min}$ of $\mathrm{ACTH}$ injection. At the end of treatment, 19/37 subjects demonstrated normal responses to ACTH, and 18 subjects had abnormal responses (serum cortisol outside of normal limits) (Table 3). The 18 subjects returned in 2 weeks, and after a second low-dose stimulation test, 16/18 subjects had normal responses. Two subjects required a third test and one subject required a fourth test before their responses returned to normal. The two subjects who did not achieve a normal response within 2 weeks received prednisone doses of either $40 \mathrm{mg}$ or $60 \mathrm{mg}$ in the last treatment period.

\section{White blood cell counts}

Daily doses of prednisone up to $60 \mathrm{mg}$ resulted in doseand time-dependent effects on white blood cell counts. Eosinophil counts relative to placebo demonstrated acute dose-dependent reductions on Day 1. A significant reduction versus placebo was observed as early as $2 \mathrm{~h}$ post-dose with prednisone $60 \mathrm{mg}$ (Fig. 2a). At $4 \mathrm{~h}$ reductions were significant at all doses, and from 4-12 h counts relative to placebo were relatively stable (Fig. 2a). Reductions in eosinophil counts relative to placebo were seen at most doses on Day 8 (Fig. 2b).

Prednisone induced increases in neutrophil counts relative to placebo throughout Day 1, with significant increases seen with doses $\geq 10 \mathrm{mg}$ at $12 \mathrm{~h}$ post-dose (Fig. 2c). Differences in neutrophil counts relative to placebo were variable over the next 7 days: significant increases were observed with higher doses on Days 2 and 8 , whereas decreases, which were significant with the lower doses, were seen on Day 4 (Fig. 2d). 
Table 3 Number of subjects with abnormal and normal responses to ACTH stimulation tests performed every 2 weeks

\begin{tabular}{|c|c|c|c|c|c|c|c|}
\hline \multirow{3}{*}{$\begin{array}{l}\text { Treatment } \\
\text { sequence }\end{array}$} & \multirow{3}{*}{$\begin{array}{l}\text { Subjects, } \\
n\end{array}$} & \multicolumn{3}{|l|}{ Period } & \multicolumn{3}{|c|}{ Subjects with abnormal response to ACTH stimulation, $n$} \\
\hline & & 1 & 2 & 3 & Test 1 & Test $2^{\mathrm{a}}$ & Test $3^{\mathrm{b}}$ \\
\hline & & & & & $(N=37)$ & $(N=18)$ & $(N=2)$ \\
\hline A & 5 & Placebo & $2.5 \mathrm{mg}$ & $10 \mathrm{mg}$ & 3 & 0 & 0 \\
\hline B & 5 & $2.5 \mathrm{mg}$ & $5 \mathrm{mg}$ & $20 \mathrm{mg}$ & 5 & 0 & 0 \\
\hline C & 5 & $5 \mathrm{mg}$ & $10 \mathrm{mg}$ & $40 \mathrm{mg}$ & 4 & 1 & $1^{c}$ \\
\hline D & 5 & $10 \mathrm{mg}$ & $20 \mathrm{mg}$ & $60 \mathrm{mg}$ & 5 & 1 & 0 \\
\hline E & $6^{d}$ & $20 \mathrm{mg}$ & $40 \mathrm{mg}$ & Placebo & 0 & 0 & 0 \\
\hline$F$ & 5 & $40 \mathrm{mg}$ & $60 \mathrm{mg}$ & $2.5 \mathrm{mg}$ & 0 & 0 & 0 \\
\hline G & $6^{d}$ & $60 \mathrm{mg}$ & Placebo & $5 \mathrm{mg}$ & 1 & 0 & 0 \\
\hline Total & 37 & & & & 18 & 2 & 1 \\
\hline
\end{tabular}

Doses shown correspond to the daily prednisone dose administered for 7 days in each treatment period

ACTH adrenocorticotropic hormone

a Subjects who failed Test 1 were re-tested 2 weeks later

bubjects who failed Test 2 were re-tested 2 weeks later

'Returned to normal on Study Day 138

${ }^{\mathrm{d}}$ One subject in sequence $\mathrm{E}$ and one in sequence $\mathrm{G}$ discontinued the study during Period 2 and were replaced following approval by the study statistician,

therefore $n=6$ in these groups for this analysis

As was observed with neutrophil counts, lymphocyte counts demonstrated acute dose-dependent reductions versus placebo on Day 1, with significant reductions observed with all doses as early as $2 \mathrm{~h}$ post-dose (Fig. 2e). Reductions in lymphocyte counts relative to placebo were greatest with most doses at $4 \mathrm{~h}$ post-dose, and were similar to placebo with the lower doses at $12 \mathrm{~h}$ post-dose (Fig. 2e). Lymphocyte counts relative to placebo continued to rise over the treatment period, and significant increases were seen with prednisone doses $\geq 10 \mathrm{mg}$ on Day 8 (Fig. 2f).

\section{Bone metabolism}

Daily doses of prednisone up to $60 \mathrm{mg}$ resulted in doseand time-dependent effects on biomarkers of bone metabolism. OC and P1NP are biomarkers of bone formation. On Day 1, plasma OC significantly decreased relative to placebo as early as $2 \mathrm{~h}$ post-dose, and continued to decrease in a dose-dependent manner until $12 \mathrm{~h}$ post-dose (Fig. 3a). Reductions in plasma OC relative to placebo were significant for doses $\geq 5 \mathrm{mg}$ on Day 2, and for all doses on Day 8 (Fig. 3b). P1NP was significantly reduced versus placebo with prednisone doses $\geq 20 \mathrm{mg}$ on Day 1 (Fig. 3c). P1NP levels increased slightly relative to placebo on Day 2, and then decreased in a dose- and timedependent manner until Day 8 (Fig. 3c).

Urinary NTX is a biomarker of bone loss. A significant increase in uNTX normalized for $\mathrm{uCr}(\mathrm{uNTX} / \mathrm{uCr}$ ) versus placebo was observed with prednisone $60 \mathrm{mg}$ by Day 2, and further dose-dependent increases occurred from Days 4-8 (Fig. 3d).

\section{Metabolism}

The results for fasting glucose and insulin on Days 1 and 8 are shown in Table 4. Differences in serum glucose concentrations between prednisone and placebo were small but significantly lower with prednisone $5 \mathrm{mg}$ and doses $\geq 20 \mathrm{mg}$ on Day 4, and doses $\geq 40 \mathrm{mg}$ on Days 7 and 8. The effect of prednisone on glucose metabolism was tested using an OGTT on Day 6. Increases from baseline in both glucose and insulin concentrations at $0.5 \mathrm{~h}$ were observed for all prednisone doses and for placebo, followed by steady decreases for all prednisone doses at 1 and $2 \mathrm{~h}$. After 6 days of prednisone treatment, the changes from baseline in both glucose and insulin concentrations relative to placebo were not significant at most time points (data not shown).

The effect of prednisone relative to placebo on serum triglyceride levels was variable. On Day 1, prednisone $20 \mathrm{mg}$ and $40 \mathrm{mg}$ significantly raised triglyceride levels. On Day 8, prednisone raised triglyceride levels, but the relationship to dose was inconsistent, and the impact generally was not significant (Table 4). Dose- and time-dependent effects of prednisone on adiponectin were also observed relative to placebo. On Day 8, adiponectin was significantly increased with higher prednisone doses (Table 4).

\section{Central nervous system}

The results of both the POMS ${ }^{\mathrm{mm}}$ and MOS-Sleep assessments did not show any changes when comparing the values to normative samples. However, no clear pattern for the treatment arms appeared in either assessment.

\section{Safety}

There were no serious adverse events (SAEs) or deaths reported. There were no clinically significant changes in vital signs or body weight at any time point. The incidence of AEs with prednisone was not dose related. Treatmentemergent adverse events (TEAEs) were reported for two 

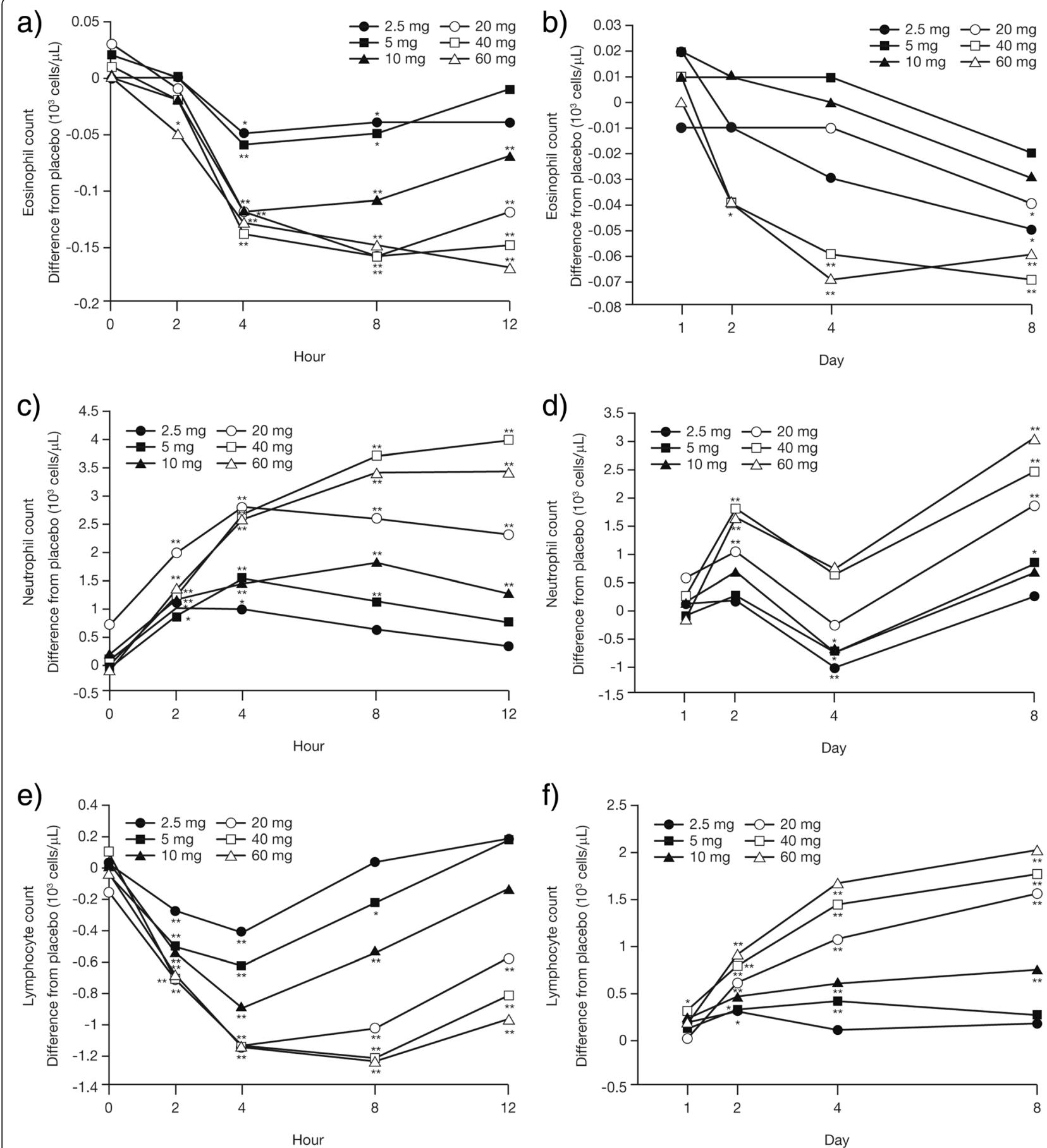

Fig. 2 Mean change from baseline (difference from placebo) in white blood cell counts. Eosinophil, neutrophil, and lymphocyte counts for Day 1 by hour $(\mathbf{a}, \mathbf{c}, \mathbf{e})$ and for Days 1 through $8(\mathbf{b}, \mathbf{d}, \mathbf{f})$ for each daily prednisone dose. ${ }^{*} P \leq 0.05$ and ${ }^{*} P \leq 0.01$ versus placebo

to eight subjects (13-50\%) across the prednisone doses and ten subjects $(67 \%)$ administered placebo. Central nervous system disorders, mainly headache, were the most frequently reported TEAEs (Table 5). Three subjects reported severe AEs; all were headaches experienced while on prednisone $2.5 \mathrm{mg}$, prednisone $20 \mathrm{mg}$, and placebo, respectively; the headache in the subject dosed with prednisone $2.5 \mathrm{mg}$ was considered by the investigator to be related to the study treatment.

Treatment-related AEs were reported by two subjects (13\%) dosed with prednisone $2.5,5,20$, and $40 \mathrm{mg}$, respectively, no subjects dosed with $10 \mathrm{mg}$, and three 

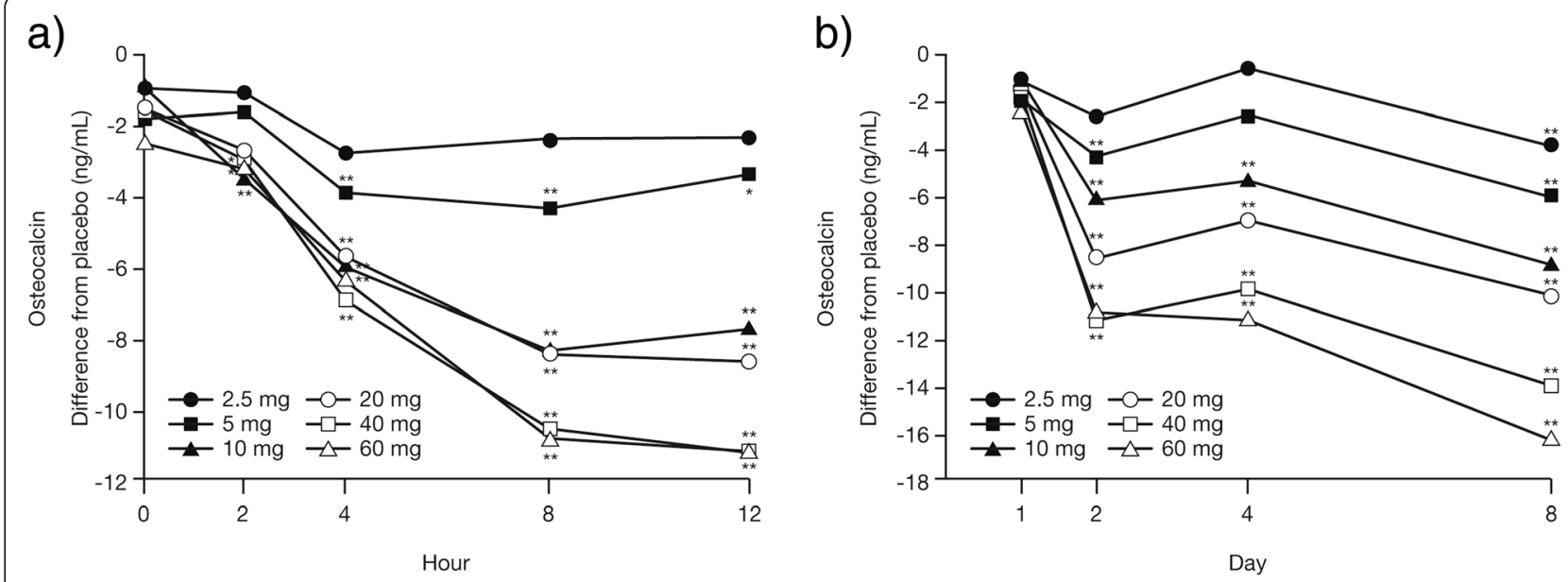

c)

d)
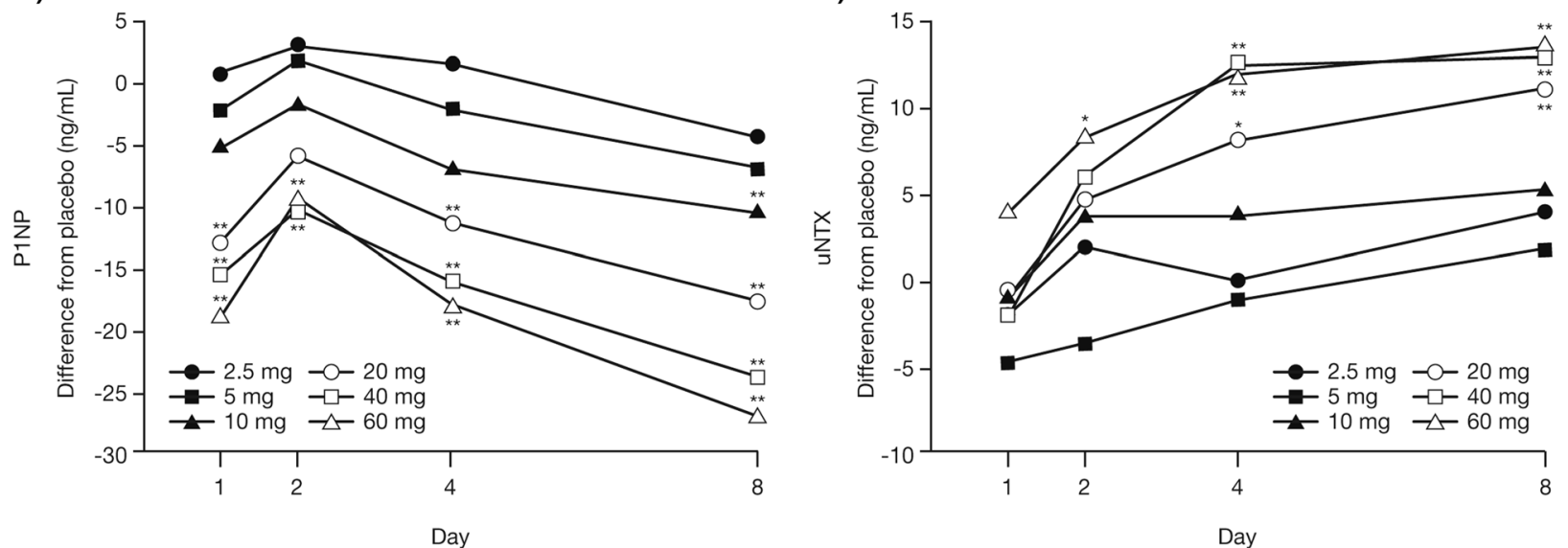

Fig. 3 Mean change from baseline (difference from placebo) in biomarkers of bone metabolism. Change in osteocalcin (OC), procollagen type $1 \mathrm{~N}$-propeptide (P1NP), and urinary N-terminal cross-linked telopeptide of type 1 collagen (UNTX) for each daily dose of prednisone. a OC: Day 1 by hour; (b) OC: Days 1-8; (c) P1NP: Days 1-8; (d) UNTX: Days 1-8. ${ }^{*} P \leq 0.05$ and ${ }^{*} P \leq 0.01$ versus placebo

Table 4 Mean differences from placebo (standard error) in fasting glucose, fasting insulin, triglycerides, and adiponectin

\begin{tabular}{llllllll}
\hline Parameter & Day & \multicolumn{2}{l}{ Prednisone $(\mathrm{mg} /$ day) } & & & \\
\cline { 2 - 7 } & & 2.5 & 5 & 10 & 20 & 40 & 60 \\
\hline Fasting glucose, $\mathrm{mg} / \mathrm{dL}$ & 1 & $1.19(1.97)$ & $3.44(1.97)$ & $1.60(1.97)$ & $0.94(1.96)$ & $1.86(1.99)$ & $2.13(1.93)$ \\
& 8 & $-2.06(2.00)$ & $-1.40(2.00)$ & $-2.11(2.00)$ & $-3.24(1.99)$ & $-6.66(2.01)^{* *}$ & $-7.10(1.97)^{* *}$ \\
Fasting insulin, $\mu \mathrm{U} / \mathrm{mL}$ & 1 & $2.15(2.90)$ & $2.24(2.81)$ & $1.69(2.90)$ & $2.10(2.89)$ & $1.21(2.83)$ & $1.76(2.90)$ \\
& 8 & $-1.44(2.34)$ & $-1.70(2.34)$ & $-0.52(2.34)$ & $-0.39(2.32)$ & $-0.50(2.34)$ & $0.71(2.31)$ \\
Triglycerides, $\mathrm{mg} / \mathrm{dL}$ & 1 & $39.19(21.19)$ & $17.93(20.20)$ & $22.60(21.16)$ & $85.79(21.12)^{* *}$ & $44.56(20.52)^{*}$ & $37.18(21.16)$ \\
& 8 & $5.43(17.01)$ & $13.56(16.95)$ & $8.82(17.01)$ & $9.66(16.95)$ & $35.59(17.09)^{*}$ & $26.42(16.76)$ \\
Adiponectin, $\mu \mathrm{g} / \mathrm{mL}$ & 1 & $-1.51(0.69)^{*}$ & $-1.61(0.67)^{*}$ & $-0.47(0.69)$ & $-1.89(0.69)^{*}$ & $-0.73(0.68)$ & $-0.18(0.69)$ \\
& 8 & $-0.27(0.58)$ & $-0.63(0.58)$ & $0.02(0.58)$ & $1.00(0.58)$ & $2.46(0.58)^{* *}$ & $2.47(0.57)^{* *}$ \\
\hline
\end{tabular}


Table 5 Treatment-emergent adverse events (all events that occurred in $>1$ subject)

\begin{tabular}{|c|c|c|c|c|c|c|c|}
\hline \multirow[t]{4}{*}{ TEAE } & \multicolumn{7}{|c|}{ TEAEs, $n(\%)$} \\
\hline & \multirow{3}{*}{$\begin{array}{l}\text { Placebo } \\
(n=15)\end{array}$} & \multicolumn{6}{|c|}{ Prednisone (mg/day) } \\
\hline & & 2.5 & 5 & 10 & 20 & 40 & 60 \\
\hline & & $(n=15)$ & $(n=15)$ & $(n=15)$ & $(n=16)$ & $(n=15)$ & $(n=16)$ \\
\hline Total & $10(67)$ & $6(40)$ & $5(33)$ & $2(13)$ & $8(50)$ & $3(20)$ & $4(25)$ \\
\hline Headache & $4(27)$ & $4(27)$ & $1(7)$ & 0 & $4(25)$ & $2(13)$ & $3(19)$ \\
\hline Nasopharyngitis & $1(7)$ & 0 & $2(13)$ & $1(7)$ & 0 & 0 & $1(6)$ \\
\hline Pharyngolaryngeal pain & 0 & $1(7)$ & $1(7)$ & 0 & $1(6)$ & $1(7)$ & 0 \\
\hline Cough & 0 & 0 & $1(7)$ & $1(7)$ & $1(6)$ & 0 & 0 \\
\hline Dyshidrosis & $1(7)$ & 0 & 0 & 0 & $1(6)$ & $1(7)$ & 0 \\
\hline Dyspepsia & 0 & 0 & $1(7)$ & 0 & $1(6)$ & $1(7)$ & 0 \\
\hline Abdominal pain, upper & 0 & $1(7)$ & 0 & 0 & 0 & 0 & $1(6)$ \\
\hline Dermatitis, contact & 0 & $1(7)$ & $1(7)$ & 0 & 0 & 0 & 0 \\
\hline Dizziness & $1(7)$ & 0 & 0 & 0 & 0 & 0 & $1(6)$ \\
\hline Dysmenorrhea & 0 & 0 & 0 & 0 & $1(6)$ & 0 & $1(6)$ \\
\hline Furuncle & $1(7)$ & 0 & $1(7)$ & 0 & 0 & 0 & 0 \\
\hline Nausea & 0 & 0 & 0 & 0 & 0 & $1(7)$ & $1(6)$ \\
\hline Pyrexia & $1(7)$ & 0 & $1(7)$ & 0 & 0 & 0 & 0 \\
\hline
\end{tabular}

TEAE treatment-emergent adverse event

subjects (19\%) dosed with $60 \mathrm{mg}$. Treatment-related AEs were reported by four subjects $(27 \%)$ dosed with placebo. Headache was the most frequently reported treatment-related $\mathrm{AE}$, occurring in one or two subjects (6 \% or $13 \%$ ) across the prednisone doses and one subject dosed with placebo.

\section{Discussion}

This study was designed to characterize the dose-response and time course of prednisone effects on biomarkers of GC receptor agonism in a healthy adult population over 7 days. Daily doses of prednisone up to $60 \mathrm{mg}$ were generally welltolerated and resulted in dose- and time-dependent effects on a number of biomarkers. As would be expected, a decrease relative to placebo was noted in biomarkers of bone formation ( $\mathrm{OC}$ and $\mathrm{P} 1 \mathrm{NP})$, whereas there was an increase in a biomarker of bone turnover (uNTX). Also as expected, suppression of morning cortisol levels was seen at higher prednisone doses. Metabolic effects on glucose concentrations, OGTT, and triglyceride levels were modest and generally not statistically significant; however, adiponectin levels were significantly increased relative to placebo with higher prednisone doses by Day 8 .

GCs are reasonably safe for short-term use. However, serious complications have often been reported with long-term use $[10,11]$. In this study, inhibition of the HPA axis was evident by the potent, dose-dependent suppression of serum cortisol following the first dose of prednisone. As expected, with regard to the low-dose ACTH stimulation test, the subjects that took longer to return to normal were in the treatment groups that received the higher doses of prednisone in Period 3.

GCs are well known for their ability to affect circulating white blood cell profiles. It is generally acknowledged that administration of GC induces a transient fall in circulating lymphocytes, which is maximal 4-6 h after administration [19], particularly if the drug is administered in the morning [20]; this is thought to arise mainly from a reduced efflux of lymphocytes from lymphoid organs [13]. The transient fall is followed by a subsequent return to normal values within 12-24 h [19]. This was demonstrated in the present study, where all doses of prednisone reduced lymphocyte counts within $2 \mathrm{~h}$, with maximum effect seen at 4-8 h. Levels started to return towards normal by $8 \mathrm{~h}$ after dosing, and were close to baseline values by $24 \mathrm{~h}$. Repeated dosing with prednisone resulted in dose-dependent increases in lymphocyte counts, with the stimulation maintained for doses $\geq 10 \mathrm{mg}$ on Day 8 . The increases in lymphocyte count on the mornings prior to dosing were likely due to a rebound phenomenon reported previously for GCs [21]. Conversely, the dose-dependent decreases in eosinophils observed in the first $24 \mathrm{~h}$ continued through Day 8, albeit at a diminishing rate. The increased neutrophil counts observed following GC treatment are consistent with the literature, and are thought to be due to increased release from bone marrow and decreased movement out of the blood into tissue sites [21, 22].

Osteoporosis, a condition characterized mainly by a reduction in bone mineral density (BMD), is a wellestablished side effect of chronic GC therapy. In fact, 
chronic use of GCs increases the already increased risk of osteoporosis in patients with RA by twofold [23, 24]. Some studies suggest that the associated fractures actually occur at higher BMD levels in patients treated with GCs than in patients not treated with GCs [25]. However, lowdose GC therapy has been recognized to avert the deleterious effects of GCs seen at higher doses, possibly due its anti-inflammatory effect countering the bone loss caused by chronic inflammation; a literature review on the safety of long-term, low-dose GC therapy in patients with rheumatic diseases demonstrated that AEs can in fact be quite modest [26]. For example, the data from four extensively reviewed randomized controlled trials showed that BMD loss over 2 years of low-dose prednisone treatment is not significantly different from that with placebo. On the other hand, osteoporosis is still likely to be the most common side effect of chronic low-dose GC therapy [27].

Many studies maintain the idea that reduced bone formation is predominantly responsible for the GCassociated bone loss $[28,29]$. OC, an osteoblast-derived protein involved in bone formation, is routinely utilized as a biomarker because of its close association with BMD [30]. In this study, plasma OC levels were significantly reduced as early as $2 \mathrm{~h}$ after the first administered prednisone doses above $10 \mathrm{mg}$ on Day 1 . This decrease was maintained throughout Day 1 and, consistent with the literature [31, 32], throughout the treatment period. A similar trend was also observed for P1NP, another biomarker of bone formation. Furthermore, prednisone increased uNTX, a biomarker of bone loss. Taken together, these data support both decreased bone formation and increased resorption, and demonstrate dose- and time-dependent effects of daily prednisone. Interestingly, biomarkers of bone turnover are thought to be useful in predicting the rate of bone loss in postmenopausal women [33]. In addition, some of these biomarkers, such as urinary $\mathrm{C}$-telopeptide and free deoxypyridinoline, predict the associated threat of hip fracture independently of BMD [34], which is thought to be the most important predictor of osteoporotic fracture [35]. It has also been reported that several of these markers, such as serum OC and the CrossLaps peptide of urinary C-telopeptide, may be used to monitor the efficacy of therapy in patients with osteoporosis [36]. Furthermore, Garnero et al. reported that the rate of bone turnover plays an increasing role as a determinant of bone mass with increasing time following menopause, with high bone turnover being associated with low bone mass, and suggests that bone marker assessment may be useful in the evaluation of osteoporosis risk [37]. Thus, the bone biomarker data in the present study have potential predictive value for subsequent bonerelated AEs of GCs.

This study carefully and thoroughly characterized the dose-response of prednisone on two significant safety concerns associated with use of GC: HPA axis suppression and adverse effects on bone metabolism. The dose- and time-dependent responses to prednisone on the HPA axis and bone biomarkers can be used for comparison with novel glucocorticoid receptor agonists. To demonstrate preliminary evidence of dissociation, however, it is essential to characterize dose-response for putative antiinflammatory biomarkers of GCs. In healthy volunteers there is no ongoing inflammation that can be assessed for evidence of dose-dependent suppression. The effects on trafficking of circulating leukocytes may serve as a biomarker for anti-inflammatory effects in healthy volunteers. While not true anti-inflammatory biomarkers, they are likely to be associated with similar GC agonistic effects.

\section{Conclusions}

This characterization of the dose-response of prednisone on various biomarkers of $\mathrm{GC}$ agonism provides important and relevant information on safety and PD responses associated with short-term prednisone dosing over the commonly used clinical dose range, and provides a reference for early clinical development of dissociated agents targeting a differentiated PD profile.

\section{Abbreviations \\ $A C T H$, adrenocorticotropic hormone; $A E$, adverse event; BMD, bone mineral density; DAGR, dissociated agonist of the glucocorticoid receptor; GC, glucocorticoid; HPA, hypothalamic-pituitary-adrenal; MOS-Sleep, med- ical outcomes study: sleep scale; OC, osteocalcin; OGT, oral glucose toler- ance test; P1NP, procollagen type $1 \mathrm{~N}$-propeptide; PD, pharmacodynamics; POMS $^{T M}$, profile of mood state; RA, rheumatoid arthritis; TEAE, treatment- emergent adverse event; uCR, urinary creatinine; UNTX, urinary N-terminal cross-linked telopeptide of type 1 collagen}

\section{Acknowledgements}

The authors would like to thank the A9001309 study team as well as Charles Mebus, PhD, former DAGR Research Lead, Thomas C. Stock, DO, former DAGR Clinical Lead. Pfizer personnel were involved in protocol development, conducting the study, data analysis and interpretation, and the decision to submit the manuscript for publication. Editorial support was provided by Gary Dever, PhD, at Complete Medical Communications.

\section{Funding}

This study was sponsored by Pfizer Inc. Editorial support was provided by Complete Medical Communications and was funded by Pfizer Inc.

\section{Availability of data and materials}

Original data sources supporting the results of this manuscript can be made available on request from the corresponding author.

\section{Authors' contributions}

DLF, AM, FSW, and BGZ contributed to study design, analysis, and interpretation. SD participated in study conduct. All authors contributed to, read, and approved the final manuscript.

\section{Competing interests}

DLF and AM are employees of Pfizer Inc and own stock in Pfizer Inc. FSW and BGZ were employees of Pfizer at the time of the study, and FSW owns stock in Pfizer Inc. SD and BGZ have no current financial interests to disclose.

Consent for publication Not applicable. 


\section{Ethics approval and consent to participate}

The final protocol, any amendments, and informed consent documentation were reviewed and approved by the Institutional Review Board of Jasper Clinic, Inc. (Kalamazoo, MI, USA). All subjects provided written, informed consent to participate in the study. The study was conducted in compliance with the ethical principles originating in or derived from the Declaration of Helsinki and in compliance with all International Conference on Harmonisation Good Clinical Practice guidelines.

\section{Author details}

${ }^{1}$ Pfizer Inc, Eastern Point Rd, Groton, CT 06340, USA. ${ }^{2}$ Innovative Analytics, 161 East Michigan Ave, Kalamazoo, Ml 49007, USA. ${ }^{3}$ Jasper Clinic Inc, 526 Jasper Street, Kalamazoo, MI, USA. ${ }^{4}$ Astellas Pharma Global Development, Northbrook, IL 60062, USA.

Received: 4 December 2015 Accepted: 11 June 2016

Published online: 16 July 2016

\section{References}

1. Abroug F, Ouanes I, Abroug S, Dachraoui F, Abdallah SB, Hammouda Z, Ouanes-Besbes L. Systemic corticosteroids in acute exacerbation of COPD: a meta-analysis of controlled studies with emphasis on ICU patients. Ann Intensive Care. 2014;4:32.

2. Chung KF, Caramori G, Adcock IM. Inhaled corticosteroids as combination therapy with beta-adrenergic agonists in airways disease: present and future. Eur J Clin Pharmacol. 2009;65:853-71.

3. Morand EF. Effects of glucocorticoids on inflammation and arthritis. Curr Opin Rheumatol. 2007;19:302-7.

4. Liu D, Ahmet A, Ward L, Krishnamoorthy P, Mandelcorn ED, Leigh R, Brown JP, Cohen A, Kim H. A practical guide to the monitoring and management of the complications of systemic corticosteroid therapy. Allergy Asthma Clin Immunol. 2013;9:30.

5. McDonough AK, Curtis JR, Saag KG. The epidemiology of glucocorticoidassociated adverse events. Curr Opin Rheumatol. 2008;20:131-7.

6. Engvall IL, Brismar K, Hafstrom I, Tengstrand B. Treatment with low-dose prednisolone is associated with altered body composition but no difference in bone mineral density in rheumatoid arthritis patients: a controlled crosssectional study. Scand J Rheumatol. 2011;40:161-8.

7. Krasselt M, Baerwald C. The current relevance and use of prednisone in rheumatoid arthritis. Expert Rev Clin Immunol. 2014;10:557-71.

8. Pearce G, Tabensky DA, Delmas PD, Baker HW, Seeman E. Corticosteroidinduced bone loss in men. J Clin Endocrinol Metab. 1998;83:801-6.

9. van Staa TP, Leufkens HG, Cooper C. The epidemiology of corticosteroidinduced osteoporosis: a meta-analysis. Osteoporos Int. 2002;13:777-87.

10. Henzen C, Suter A, Lerch E, Urbinelli R, Schorno XH, Briner VA. Suppression and recovery of adrenal response after short-term, high-dose glucocorticoid treatment. Lancet. 2000;355:542-5.

11. Kirwan JR, Hickey SH, Hallgren R, Mielants H, Bjorck E, Persson T, Wollheim FA. The effect of therapeutic glucocorticoids on the adrenal response in a randomized controlled trial in patients with rheumatoid arthritis. Arthritis Rheum. 2006;54:1415-21.

12. Bernatsky S, Hudson M, Suissa S. Anti-rheumatic drug use and risk of serious infections in rheumatoid arthritis. Rheumatology (Oxford). 2007:46:1157-60.

13. Bloemena $E$, Weinreich S, Schellekens PT. The influence of prednisolone on the recirculation of peripheral blood lymphocytes in vivo. Clin Exp Immunol. 1990;80:460-6.

14. Cavalcanti DM, Lotufo CM, Borelli P, Ferreira ZS, Markus RP, Farsky SH. Endogenous glucocorticoids control neutrophil mobilization from bone marrow to blood and tissues in non-inflammatory conditions. $\mathrm{Br} J$ Pharmacol. 2007;152:1291-300.

15. Schacke H, Schottelius A, Docke WD, Strehlke P, Jaroch S, Schmees N, Rehwinkel $\mathrm{H}$, Hennekes $\mathrm{H}$, Asadullah K. Dissociation of transactivation from transrepression by a selective glucocorticoid receptor agonist leads to separation of therapeutic effects from side effects. Proc Natl Acad Sci U S A. 2004; 101:227-32.

16. Stock T, Fleishaker D, Wang X, Mukherjee A, Mebus C. Phase 2 evaluation of PF-04171327, a dissociated agonist of teh glucocorticoid receptor, for the treatment of rheumatoid arthritis in patients with an inadequate response to methotrexate. Arthritis Rheum. 2013;65 Suppl 10:2336.

17. Berlin M. Recent advances in the development of novel glucocorticoid receptor modulators. Expert Opin Ther Pat. 2010;20:855-73.
18. Stock T, Fleishaker D, Mukherjee A, Le V, Xu J, Zeiher B. Evaluation of Safety, Pharmacokinetics and Pharmacodynamics of a Selective Glucocorticoid Receptor Modulator (SGRM) in Healthy Volunteers. Arthritis Rheum. 2009;60: 420.

19. Fauci AS, Dale DC. The effect of Hydrocortisone on the kinetics of normal human lymphocytes. Blood. 1975;46:235-43.

20. Xu J, Winkler J, Sabarinath SN, Derendorf H. Assessment of the impact of dosing time on the pharmacokinetics/pharmacodynamics of prednisolone. AAPS J. 2008;10:331-41.

21. Mager DE, Lin SX, Blum RA, Lates CD, Jusko WJ. Dose equivalency evaluation of major corticosteroids: pharmacokinetics and cell trafficking and cortisol dynamics. J Clin Pharmacol. 2003;43:1216-27.

22. Fauci AS, Dale DC, Balow JE. Glucocorticosteroid therapy: mechanisms of action and clinical considerations. Ann Intern Med. 1976;84:304-15.

23. Saag KG, Koehnke R, Caldwell JR, Brasington R, Burmeister LF, Zimmerman B, Kohler JA, Furst DE. Low dose long-term corticosteroid therapy in rheumatoid arthritis: an analysis of serious adverse events. Am J Med. 1994;96:115-23.

24. Verhoeven AC, Boers M. Limited bone loss due to corticosteroids; a systematic review of prospective studies in rheumatoid arthritis and other diseases. J Rheumatol. 1997;24:1495-503.

25. Sambrook P, Lane NE. Corticosteroid osteoporosis. Best Pract Res Clin Rheumatol. 2001;15:401-13.

26. Da Silva JA, Jacobs JW, Kirwan JR, Boers M, Saag KG, Ines LB, de Koning EJ, Buttgereit F, Cutolo M, Capell H, Rau R, Bijlsma JW. Safety of low dose glucocorticoid treatment in rheumatoid arthritis: published evidence and prospective trial data. Ann Rheum Dis. 2006:65:285-93.

27. Bouvard B, Legrand E, Audran M, Chappard D. Glucocorticoid-induced osteoporosis: a review. Clin Rev Bone Miner Metab. 2010;8:15-26.

28. Hall GM, Spector TD, Delmas PD. Markers of bone metabolism in postmenopausal women with rheumatoid arthritis. Effects of corticosteroids and hormone replacement therapy. Arthritis Rheum. 1995;38:902-6.

29. Prummel MF, Wiersinga WM, Lips P, Sanders GT, Sauerwein HP. The course of biochemical parameters of bone turnover during treatment with corticosteroids. J Clin Endocrinol Metab. 1991;72:382-6.

30. Hari Kumar KV, Muthukrishnan J, Verma A, Modi KD. Correlation between bone markers and bone mineral density in postmenopausal women with osteoporosis. Endocr Pract. 2008:14:1102-7.

31. Godschalk MF, Downs RW. Effect of short-term glucocorticoids on serum osteocalcin in healthy young men. J Bone Miner Res. 1988;3:113-5.

32. Lems WF, Jacobs JW, Van Rijn HJ, Bijlsma JW. Changes in calcium and bone metabolism during treatment with low dose prednisone in young, healthy, male volunteers. Clin Rheumatol. 1995;14:420-4.

33. Garnero P, Sornay-Rendu E, Duboeuf F, Delmas PD. Markers of bone turnover predict postmenopausal forearm bone loss over 4 years: the OFELY study. J Bone Miner Res. 1999;14:1614-21.

34. Garnero P, Hausherr E, Chapuy MC, Marcelli C, Grandjean H, Muller C, Cormier C, Breart G, Meunier PJ, Delmas PD. Markers of bone resorption predict hip fracture in elderly women: the EPIDOS Prospective Study. J Bone Miner Res. 1996;11:1531-8.

35. Cummings SR, Black DM, Nevitt MC, Browner W, Cauley J, Ensrud K, Genant HK, Palermo L, Scott J, Vogt TM. Bone density at various sites for prediction of hip fractures. The Study of Osteoporotic Fractures Research Group. Lancet. 1993;341:72-5.

36. Meunier PJ, Confavreux E, Tupinon I, Hardouin C, Delmas PD, Balena R. Prevention of early postmenopausal bone loss with cyclical etidronate therapy (a double-blind, placebo-controlled study and 1-year follow-up). J Clin Endocrinol Metab. 1997:82:2784-91.

37. Garnero P, Sornay-Rendu E, Chapuy MC, Delmas PD. Increased bone turnover in late postmenopausal women is a major determinant of osteoporosis. J Bone Miner Res. 1996;11:337-49. 